\title{
Quantitative Evaluation of Acetaminophen in Oral Solutions by Dispersive Raman Spectroscopy for Quality Control
}

\author{
Viviane G. Borio, ${ }^{1}$ Rubens Vinha Jr., ${ }^{2}$ Renata A. Nicolau, ${ }^{3}$ \\ Hueder Paulo M. de Oliveira, ${ }^{4}$ Carlos J. de Lima, ${ }^{1}$ and Landulfo Silveira Jr. ${ }^{1}$ \\ ${ }^{1}$ Biomedical Engineering Institute, Universidade Camilo Castelo Branco (Unicastelo), \\ Parque Tecnológico de São José dos Campos, Rod. Presidente Dutra Km 138, \\ 12247-004 São José dos Campos, SP, Brazil \\ ${ }^{2}$ Fundação Armando Álvares Penteado (FAAP), Avenida Dr. Jorge Zarur 650, \\ 12242-020 São José dos Campos, SP, Brazil \\ ${ }^{3}$ Institute of Research and Development-IP\&D, Universidade do Vale do Paraíba (Univap), \\ Avenida Shishima Hifumi 2911, 12244-000 São José dos Campos, SP, Brazil \\ ${ }^{4}$ Center for Chemical Sciences, Pharmaceutical and Food, Universidade Federal de Pelotas (UFPel), \\ University Campus of Capão do Leão, P.O. Box 354, 96010-900 Pelotas, RS, Brazil \\ Correspondence should be addressed to Landulfo Silveira Jr., landulfo.silveira@gmail.com \\ Copyright (C) 2012 Viviane G. Borio et al. This is an open access article distributed under the Creative Commons Attribution \\ License, which permits unrestricted use, distribution, and reproduction in any medium, provided the original work is properly \\ cited.

\begin{abstract}
This work used dispersive Raman spectroscopy to evaluate acetaminophen in commercially available formulations as an analytical methodology for quality control in the pharmaceutical industry. Raman spectra were collected using a near-infrared dispersive Raman spectrometer $(830 \mathrm{~nm}, 50 \mathrm{~mW}, 20 \mathrm{~s}$ exposure time) coupled to a fiber optic probe. Solutions of acetaminophen diluted in excipient ( 70 to $120 \%$ of the commercial concentration of $200 \mathrm{mg} / \mathrm{mL}$ ) were used to develop a calibration model based on partial least squares (PLSs) applied to Raman spectra of solutions and, subsequently, obtain linearity, accuracy, precision (repeatability), and sensitivity of the method using the near-infrared spectroscopy (NIRS) as a gold standard method. This model was used to predict the acetaminophen concentration in commercial samples from different lots of acetaminophen formulations $(200 \mathrm{mg} / \mathrm{mL})$ with a PLS-prediction error of about $0.6 \%$. Commercial medicines had PLS predicted concentrations errors below $2.5 \%$, whereas NIRS had an error of about $3.7 \%$ compared to the label concentration. It has been demonstrated the applicability of Raman spectroscopy with fiber probe for quality control in pharmaceutical industry of commercial formulations.
\end{abstract}

Keywords: Raman spectroscopy, NIRS, acetaminophen, quantitative analysis, partial least squares

\section{Introduction}

The acetaminophen is a well-known analgesic and antipyretic that has been widely used because of the low side effects and still being well tolerated when administered in therapeutic quantities. Routine techniques for measuring acetaminophen include chromatographic methods (high performance 
liquid chromatography-HPLC), spectrophotometric methods (ultraviolet/visible, near-infrared and infrared spectroscopy, including Fourier-transform near-infrared spectroscopy (NIRS), and fluorescence spectroscopy), flow-injection spectroscopy, chemiluminescence methods, capillary electrophoretic methods, and electroanalytical methods [1].

The classical techniques for pharmaceutical drugs evaluation, such as chromatography, are sensitive and very specific, but these techniques are time consuming and of high costs, needing samples to undergo a preprocessing prior analysis, which may ultimately destroy the sample. To address this problem, optical methods have been proposed for the quantitative determination of active pharmaceutical ingredients (APIs) in drugs and medicines, most of them based on absorption and reflectance spectrometric techniques in the ultraviolet-visible and infrared regions [2, 3], with advantages such as rapid API evaluation with minimum or even without sample destruction [4].

Vibrational spectroscopy such as NIRS and Raman spectroscopy have advantages which lie on spectral selectivity and representativity and have been proposed as a quality control tool. The NIRS has grown substantially as a quality control technique in the pharmaceutical industry, including analysis of acetaminophen [5]. It allows chemical and physical information about samples to be derived from spectra. However, due to the nature of NIRS data (dependent of changes in the molecular dipole moment) and high sensitivity of water bonds, the low sensitivity of the technique restricts its scope to major components. Moreover, near-infrared spectra exhibit strong overlap [6]. Raman spectroscopy provides information about the chemical structure, that is, the molecular composition of the material under study, as well as its quantification [7, 8]. Dispersive Raman spectrometer makes possible a fast scanning/imaging through the use of an imaging spectrograph and multichannel detector such as CCD (charge-coupled device) camera [8], with lower intrinsic fluorescence by using near-infrared excitation (785 and $830 \mathrm{~nm}$ wavelength) [8-10].

Raman spectroscopy has been used in the quantitative analysis of API, noninvasively and nondestructively, with advantages such as the need for small amount of sample, virtually no sample preparation, no sample destruction, and short time to perform the analysis [4]. Raman spectra can be obtained from different pharmaceutical presentations, even directly in the container, aiming the quantification of the API and other formulation constituents with low error $[6,7,11]$. Raman spectra could be obtained direct in biological tissues, quantifying injected drugs in situ [4].

Chemometric techniques such as partial least squares (PLSs) have been used in the analytical chemistry in order to predict the amount of a specific compound in a sample using the spectral information [12]. Chemometrics have a great significance in the pharmaceutical area, since it deals with the analysis of chemical data of multivariate nature, collected through multichannel detectors, where the intensities of the signal in different wavelengths are recorded in one single spectrum [13]. Chemometrics uses mathematical and statistical methods to provide as much chemical information as possible with the analysis of the obtained data, even in the presence of experimental noise, interferences of unknown nature, collinearities, and nonlinearities, besides it is sufficiently robust to allow no need for changes in the input parameters with the inclusion of new samples to the model [12-14].

The process analytical technology (PAT) aims at the development of strategies to the control of the production processes in the pharmaceutical industry [15-17]. The PAT Guide attempted for the need for research into new and faster analytical methodologies for quality control of drugs to be used on-line and at-line. Optical techniques and multivariate statistics such as PLS have been claimed for a consistent, reliable, rapid, and low-cost analysis of chemical species in the industrial field for analytical 
Table 1: Set of acetaminophen solutions, respective nominal concentrations, and solvents used in the dilution.

\begin{tabular}{lccc}
\hline Sample & $\begin{array}{c}\text { API nominal concentration } \\
(\mathrm{mg} / \mathrm{mL})\end{array}$ & $\begin{array}{c}\text { API nominal } \\
\text { concentration }(\%)\end{array}$ & Solvent \\
\hline $\mathrm{J}$ & 0 & 0 & Excipient \\
$\mathrm{D}$ & 140 & 70 & Excipient \\
$\mathrm{H}$ & 160 & 80 & Excipient \\
$\mathrm{C}$ & 180 & 90 & Excipient \\
$\mathrm{B}$ & 190 & 95 & Excipient \\
$\mathrm{G}$ & 200 & 100 & Excipient \\
$\mathrm{PEG}$ & 200 & 100 & Polyethylene glycol \\
$\mathrm{A}$ & 210 & 105 & Excipient \\
$\mathrm{I}$ & 220 & 110 & Excipient \\
$\mathrm{E}$ & 240 & 120 & Excipient \\
$\mathrm{F}^{*}$ & 260 & 130 & Excipient \\
\hline
\end{tabular}

${ }^{*}$ Solution $\mathrm{F}$ was excluded due to problems of acetaminophen solubilization.

instrumentation [15-17], which could successfully attend the PAT requirements. In conjunction, the Expert Working Group under the International Conference on Harmonisation of Technical Requirements for Registration of Pharmaceuticals for Human Use (ICH) developed guidelines and set parameters to be determined in order to validate the analytical techniques [18, 19], according to PAT directions.

The purpose of this study was to assess the feasibility of a quantitative evaluation of acetaminophen (commercial drop's presentation) based on dispersive Raman spectroscopy using fiber optic probe and multivariate statistics PLS (RS/PLS quantitative model) and to verify selectivity, linearity, range, precision, and accuracy, in order to check the ability of Raman spectra and PLS to be used as an analytical technique to attend industries requirements and compare with the NIRS technique already used for this. The developed model was then employed to predict the concentration of acetaminophen in samples of commercial medicines containing this API with $200 \mathrm{mg} / \mathrm{mL}$ (drop's), aiming at its use as an analytical technique of choice. The results were compared to the ones obtained by NIRS, assigned by the manufacturer of the drugs.

\section{Material and Methods}

\subsection{Solutions Preparation}

Solutions of nine different concentrations of acetaminophen were prepared by the laboratory of a leading manufacturer, representing the range from 70 to $130 \%$ of the concentration found in the commercially available drug, diluted in the same excipient used in the commercial drug (Table 1). Also, samples of the excipient (placebo) and of the API diluted in polyethylene glycol (the main component of the excipient) were obtained. The placebo is composed basically by polyethylene glycol, sodium cyclamate, sodium saccharin, sodium benzoate, sodium metabisulfite, sodium hydroxide, citric acid, yellow dye, flavors, and deionized water. The amount of each excipient component could not be revealed, because it is 


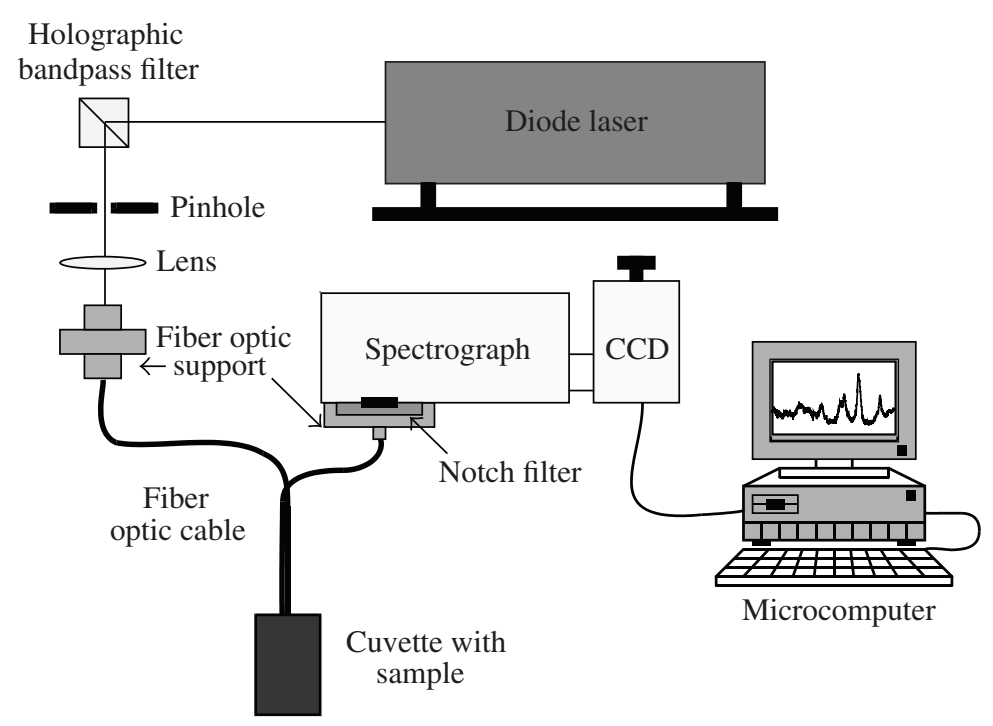

Figure 1: Schematic diagram of the dispersive Raman spectrometer used in the experiment. Fiber cable has a "six around one" configuration as described in De Lima et al. [20]. Laser power measured at fiber tip: $50 \mathrm{~mW}$, wavelength: $830 \mathrm{~nm}$, spectrometer resolution: $10 \mathrm{~cm}^{-1}$.

copyrighted. Solutions were prepared in 6 replicates (one used to develop the model and the remaining in the prediction), and the nominal concentration of acetaminophen in each solution was confirmed by the manufacturer using NIRS. The dilution of $260 \mathrm{mg} / \mathrm{mL}$ was withdrawn due to the low solubilization of the API in the excipient. Also, it was obtained six flasks of commercial medicines containing $200 \mathrm{mg} / \mathrm{mL}$ of acetaminophen (drop's presentation) from different lots in local drugstores.

\subsection{Raman Spectroscopy}

The solution samples and commercial medicines were submitted to the near-infrared dispersive Raman spectroscopy technique using the Raman spectrometer detailed elsewhere [21], connected to a fiber optic probe as shown in Figure 1. It is composed by an $830 \mathrm{~nm}$ diode laser (Micro Laser Systems Inc., Model L4830S, CA, USA), coupled to a Raman probe made up of low-OH fused-silica optical fibers with "6 collections around 1 excitation" configuration, as described elsewhere [20], using a $f=25 \mathrm{~mm}$ lens. The measured power at excitation fiber tip was about $50 \mathrm{~mW}$. Solutions and medicines were placed in a quartz cuvette of $4 \mathrm{~mL}$ for Raman measurements. The fiber optic cable distal excitation/collection end was immersed $1 \mathrm{~mm}$ inside the solution, and Raman signal was collected in about $20 \mathrm{~s}$. The signal emitted from the samples and collected through the optical cable was coupled to the entrance slit of the spectrograph (Chromex, Model 250IS, MA, USA), which had a notch filter at $830 \mathrm{~nm}$ before the entrance (Spectral Iridian Technologies, model PN-ZX 000080, ON, Canada) to reject the scattered light from the laser. The spectrograph slit was set to $150 \mu \mathrm{m}$, providing a Raman spectral resolution of about $10 \mathrm{~cm}^{-1}$ [22]. The signal dispersed by the spectrograph was detected by a liquid-nitrogen cooled CCD camera and controller (Princeton Instruments, model LN/CCD-1024-EHR1 and ST130, NJ, USA) 
connected to a computer for acquisition and storage of the spectra. Each sample was scanned at the same day and experimental conditions.

The procedures of spectra calibration, fluorescence background subtraction, cosmic rays removal, and normalization were performed using the software OriginPro 7.5 (OriginLab Corp., MA, USA). The Raman shift calibration was done by collecting the spectrum of naphthalene and correlating the spectrum band positions (pixel) with the known band shift $\left(\mathrm{cm}^{-1}\right)$ with a 3 rd-order polynomial fitting. To remove the fluorescence background, it was performed the baseline correction, in which straight lines were fitted in the spectra valleys and subtracted from the gross spectrum, remaining the high frequency Raman bands. Spectra were then normalized using the band of polyethylene glycol (main constituent of the excipient) at $1450 \mathrm{~cm}^{-1}$ and plotted in the spectral range of 600 to $1800 \mathrm{~cm}^{-1}$.

\subsection{PLS Quantitative Model}

The PLS uses the nominal concentration information to obtain factors or latent variables, which are correlated to the principal components vectors, calculated by the PCA (principal component analysis) method $[13,23]$. The first factors describe the direction of the maximum variance (the first principal components) which, in the majority of the cases, is correlated to the concentrations of the API [13, 23, 24]. A multivariate calibration model using PLS was developed with a spectral dataset of API dilutions in the concentration range of 140 to $240 \mathrm{mg} / \mathrm{mL}$. Then, this model was validated using a dataset composed of samples randomly chosen from the replicate dilutions in the same range, and the standard error of validations was calculated.

In the PLS model, the Raman spectra and the nominal concentrations were considered as independent (ordinates) and dependent (abscissas) variables, respectively, and, under Matlab 4.2 and PLS Toolbox 1.5, it was used the command $[p, q, w, t, u, b, \mathrm{ssq}]=\operatorname{pls}(x, y, 1 \mathrm{v}, 1)$ to build the model, where $x=$ spectra, $y=$ concentrations, and $\mathrm{lv}=$ number of factors (latent variables). The PLS outputs are $p=$ loading of independent variables, $q=$ loading of dependent variables, $w=$ importance of the independent variables, $t=$ scores of independent variables, $u=$ importance of the dependent variables, $b=$ vector of PLS internal coefficient, and ssqdif $=$ variances between $x$ and $y$ obtained by the PLS. Since there are only few variables that are responsible to the spectrum of the drug (acetaminophen and excipient), one expect that only a few lv are needed to build the model.

In order to define the number of $\mathrm{l} v$ to be used in the model and to predict the concentrations of the dilutions and drug samples with the least error of prediction, it was established a cross-validation procedure, using the Raman spectra (independent variables) from the replicate dataset, with the number of lv changing from 1 to 5 , through the function $y$ pred $=\operatorname{plspred}(x, b, p, q, w, 1 \mathrm{v})$. The results of the nominal concentrations versus the ones estimated by the PLS model (ypred) were plotted, and the standard error of prediction (SEP) was calculated for each lv. The purpose of the SEP is to determine the error of the PLS model when applied to a different (in our case the replicate) dataset in the same range. The SEP can be calculated as follows (using Excel function STEYX):

$$
\operatorname{SEP}(\%)=\sqrt{\frac{1}{(n-2)}\left\{\sum_{i=1}^{n}\left(C a_{i}-\bar{C} a_{i}\right)^{2}-\frac{\left[\sum_{i=1}^{n}\left(C_{i}-\bar{C}_{i}\right)\left(C a_{i}-\bar{C} a_{i}\right)\right]^{2}}{\sum_{i=1}^{n}\left(C_{i}-\bar{C}_{i}\right)^{2}}\right\}},
$$




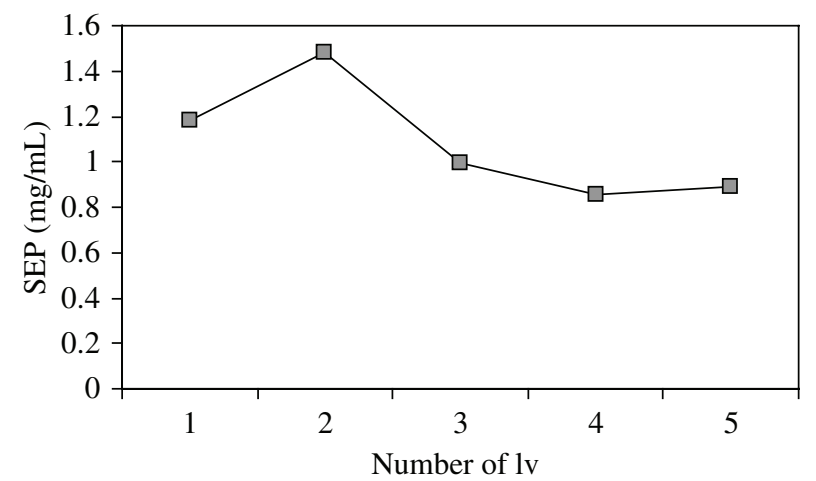

Figure 2: Standard error of prediction (SEP) of the PLS model as a function of the $1 \mathrm{v}=1$ to 5 calculated using a replicate dataset.

where $C a_{i}$ is the nominal concentration of the API, $C_{i}$ is the concentration predicted by the PLS model, and $n$ is the number of samples. Figure 2 shows the SEP values depending on the number of lv used in the cross-validation. It was found that the SEP was $1.19 \mathrm{mg} / \mathrm{mL}$ for $\mathrm{lv}=1$, increasing for $\mathrm{lv}=2$ and decreasing for higher lv values.

The spectra of dilutions and commercial drugs were then used in the PLS model as new independent variables using the number of $\mathrm{lv}=1$ and the predicted concentrations were then calculated.

\subsection{Quantitative Evaluation: Figures of Merit}

The predicted concentration of the replicate samples were used to estimate the parameters [18, 19]: range, linearity, selectivity, precision, and accuracy of the RS/PLS method.

\section{Range}

In this study, it was defined the range of $70 \%$ to $120 \%$ (140 to $240 \mathrm{mg} / \mathrm{mL}$ ), due to problems of solubility of the API at $130 \%$.

\section{Selectivity}

It is the ability of the method to measure a compound in the presence of other components, such as adjuvants. For this parameter, it was considered a solution of the acetaminophen with $200 \mathrm{mg} / \mathrm{mL}$ in pure excipient and in polyethylene glycol (6 replicates of each).

\section{Linearity}

It is the ability of the method to demonstrate whether there is proportionality between the predicted and the nominal concentrations of the API in the sample, within a specific range. This parameter was determined by constructing a curve with solutions of five concentrations: 160, 180, 200, 220, and $240 \mathrm{mg} / \mathrm{mL}$. We calculated the curve slope $(\mathrm{m})$ which determines the proportionality of the analytical 
function, the linear coefficient $(h)$, and the correlation coefficient $(r)$. The criterion for acceptance is $r=0.99$.

\section{Precision (Repeatability)}

It is referred to the agreement between the results within a short period of time with the same analyst and same instrumentation. It is done by using at least nine determinations under the linear range of the method, that is, three concentrations (low, intermediate or $100 \%$, and high) with three replications each. For the study, it was used the concentrations 160,200 , and $240 \mathrm{mg} \cdot \mathrm{mL}^{-1}$ in triplicate, totaling nine solutions. The precision was expressed as relative standard deviation (RSD), according to the formula

$$
\mathrm{RSD}=\frac{\mathrm{SD}}{\mathrm{DAC}} \times 100
$$

where SD is standard deviation and DAC is determined average concentration. The maximum RSD for the method should not exceed $5 \%$.

\section{Accuracy}

It is the closeness of the results obtained by the method under study in relation to the true value (nominal). It is obtained by adding known amounts of the drug to the components of the excipient. It was determined from nine determinations in the range of the procedure, that is, concentrations of 160, 200 , and $240 \mathrm{mg} / \mathrm{mL}$ in triplicates. The equation used to calculate the accuracy (AC) is

$$
\mathrm{AC}=\frac{\mathrm{DAC}}{\mathrm{VA}} \times 100
$$

where VA is value added.

\section{Results and Discussion}

The Raman spectra of the acetaminophen solutions in the range of 600 to $1800 \mathrm{~cm}^{-1}$, with concentrations ranging from 140 to $240 \mathrm{mg} / \mathrm{mL}$ and normalized by the band at $1450 \mathrm{~cm}^{-1}$, are shown in Figure 3. These spectra are dominated by peaks from acetaminophen and in some extent by the excipient, mainly ethylene glycol. Figure 4 shows the Raman spectra of acetaminophen: Figure 4(a) is the spectrum obtained indirectly by subtracting solution $\mathrm{G}(200 \mathrm{mg} / \mathrm{mL}$ in excipient) from solution J (only excipient); Figure 4(b) is the Raman spectra of acetaminophen, obtained from Sigma-Aldrich web page and used as a reference of band positions. It can be seen that the reference spectra present bands in the positions closer to the spectra obtained indirectly, despite a few differences in the resolution and intensity of particular bands. Therefore, the main bands of acetaminophen are, according to the literature, amide I $(\mathrm{C}=\mathrm{O})$ at $1667 \mathrm{~cm}^{-1}, \mathrm{~N}-\mathrm{H}$ at $1622 \mathrm{~cm}^{-1}$, amide II (C-N stretching, $\mathrm{N}-\mathrm{H}$ bending) at $1556 \mathrm{~cm}^{-1}, \mathrm{C}-\mathrm{H}$ at $1329 \mathrm{~cm}^{-1}$, and phenyl ring at $799 \mathrm{~cm}^{-1}$ [25-27].

By applying the PLS model in the Raman spectra of replicate samples (cross-validation) with selected number of lv, one could calculate the predicted concentration and the SEP that the model is 


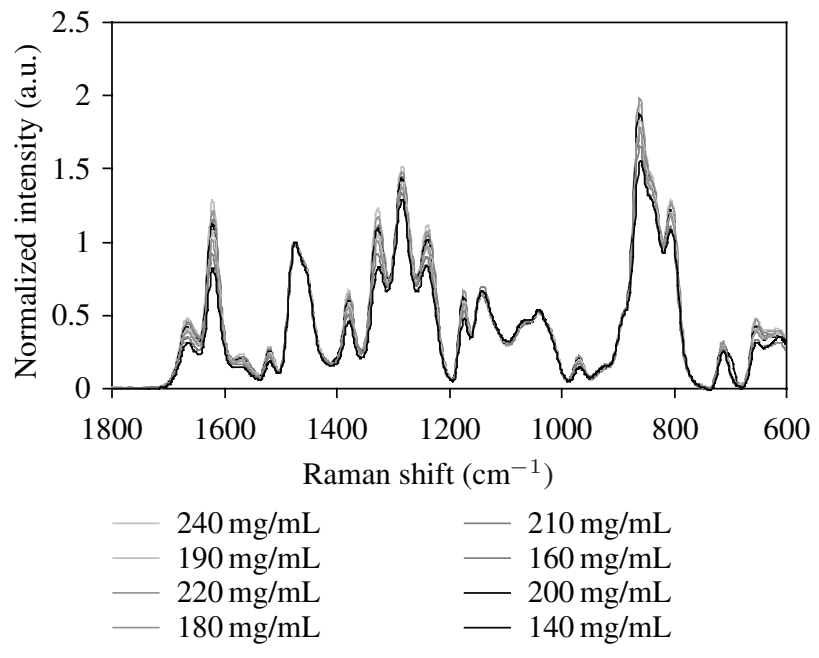

Figure 3: Normalized Raman spectra of solutions of acetaminophen diluted in excipient (placebo) ranging from 140 to $240 \mathrm{mg} / \mathrm{mL}$ and used in the calibration dataset.

subjected to. Figure 5 shows the real versus predicted concentration for the cross-validation. It can be seen an excellent agreement of the data points to the zero-error diagonal, revealing an excellent model fit. The SEP obtained in the validation procedure (using $1 \mathrm{lv}$ ) was of $1.19 \mathrm{mg} / \mathrm{mL}$ or $0.6 \%$.

The results of the parameters obtained by RS/PLS are as follows.

\section{Selectivity}

The higher relative error of acetaminophen in standard excipient compared to acetaminophen in pure PEG was $2.4 \%$, showing that the technique allows detection of the major component of the sample in different excipient (Table 2).

\section{Linearity}

It was determined the concentrations of five solutions $(160,180,200,220$, and $240 \mathrm{mg} / \mathrm{mL})$ and compared with the nominal concentration values. From the curve, it was obtained $m=1.025$ and $h=-6.204$. The linear regression coefficient obtained was $r=0.99$, indicating adequate correlation between the data predicted concentration and the dilution effectively performed.

\section{Precision (Repeatability)}

It was used three concentrations with six replicate samples of the following concentrations: 160, 200, and $240 \mathrm{mg} / \mathrm{mL}$. It was calculated the RSD for each concentration of RS/PLS compared to the nominal dilution (Table 3). The acceptance criteria established was RSD $\leq 5 \%$. For solutions with low and intermediate concentrations, the obtained RSDs were found to be below the maximum limit specified. For high concentrations, the resulting RSD was found to be $6.0 \%$, which may be due to an outlier. When 


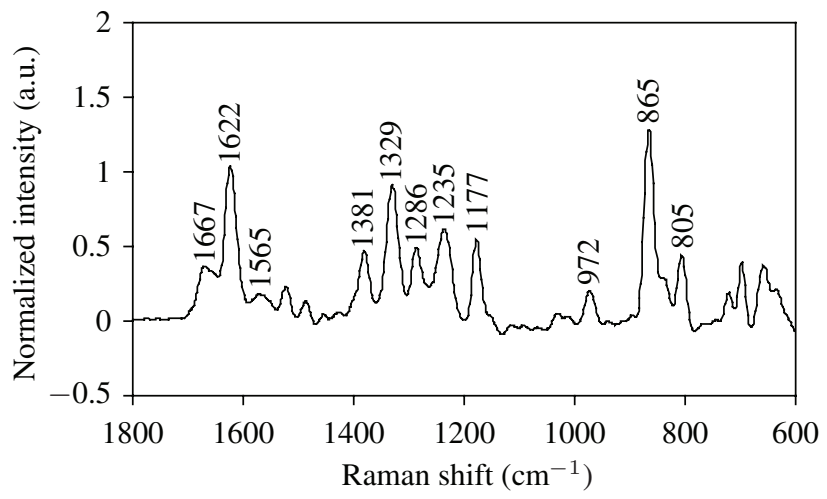

(a)

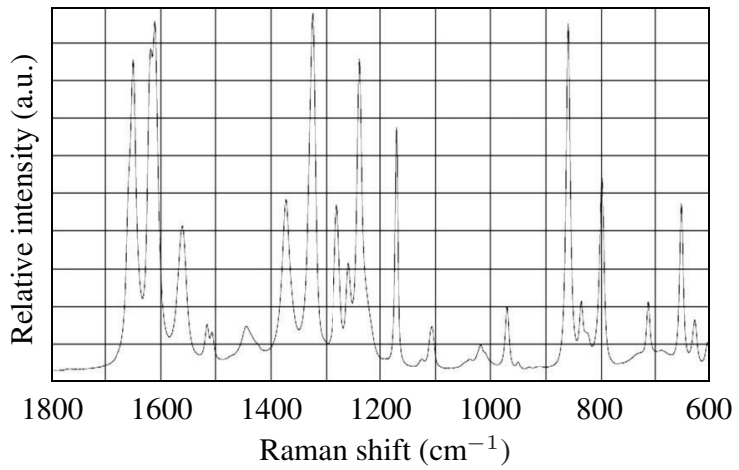

(b)

Figure 4: (a) Raman spectra of acetaminophen obtained indirectly by subtracting solution $G$ (200 mg/mL in excipient) from solution J (only excipient) and (b) Raman spectra of acetaminophen adapted from Sigma-Aldrich home page (http://www.sigmaaldrich.com/, acetaminophen number 00370, purum, $\geq 98.0 \%$, Fluka).

this outlier is withdrawn (Table 3), the error is minimized, being a RSD value comparable to the lower and intermediate concentrations.

\section{Accuracy}

It was calculated by using the predicted concentrations of the 160,200 , and $240 \mathrm{mg} / \mathrm{mL}$, in triplicate, being determined by means of RSD and recovery, as shown in Table 3. The acceptance criteria established for relative deviation were $\leq 2 \%$, being that satisfactory recovery values are found between 98 and $102 \%$. The solutions with intermediate and high concentrations showed relative deviation of 1.0 and $1.5 \%$, respectively, being within the limits of acceptance, unlike the solution of low concentration, which did not provide a satisfactory level. The same occurred with the recovery values, where the solution of low concentration showed a value of $97.1 \%$ as opposed to middle and upper solutions that showed the values 99 and $98.5 \%$, respectively. 


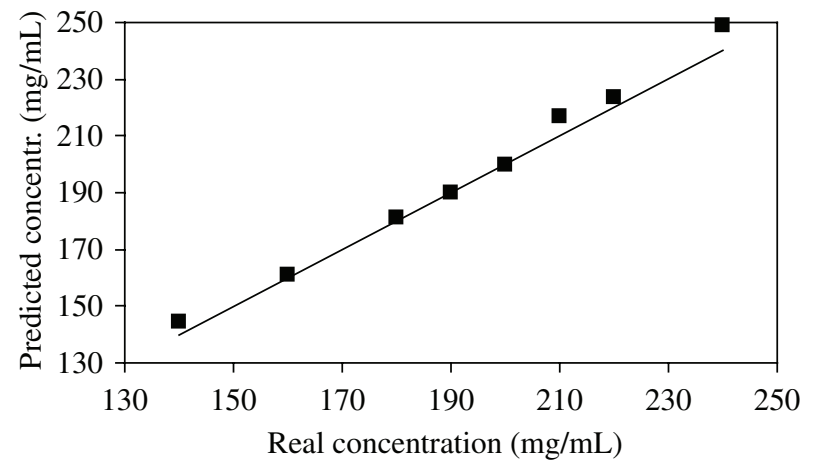

Figure 5: Real versus predicted concentrations of the RS/PLS method using the replicate dataset and $\mathrm{lv}=1 . \mathrm{SEP}=1.19 \mathrm{mg} / \mathrm{mL}(0.6 \%)$. The solid line represents the zero-error curve.

Table 2: Predicted concentrations of acetaminophen in different excipients and relative errors using the $200 \mathrm{mg} / \mathrm{mL}$ solution ( $\mathrm{G}$ and $\mathrm{PEG}$ ).

\begin{tabular}{lccc}
\hline Sample & $\begin{array}{c}\text { Predicted concentration } \\
\text { using standard excipient (\%) }\end{array}$ & $\begin{array}{c}\text { Predicted concentration using } \\
\text { polyethylene glycol (\%) }\end{array}$ & Relative error (\%) \\
\hline 1 & 99.1 & 98.9 & $0.2 \%$ \\
2 & 100.3 & 98.7 & $1.6 \%$ \\
3 & 100.2 & 98.4 & $1.8 \%$ \\
4 & 100.1 & 98.3 & $1.8 \%$ \\
5 & 99.7 & 98.2 & $1.5 \%$ \\
6 & 100.6 & 98.2 & $2.4 \%$ \\
\hline
\end{tabular}

In this work, the RS/PLS was evaluated by parameters as linearity, accuracy, and precision in the same way of Orkoula et al. and Rossignoli et al. [28, 29]. It has been shown that RS/PLS showed excellent linearity with $r=0.99$, high precision, with DPR as low as $1.7 \%$. Corroborating the method validation Orkoula et al. [28], commercial samples of the reference drug containing $200 \mathrm{mg} / \mathrm{mL}$ of acetaminophen were also used to validate the model. These samples showed very low errors, not exceeding $2.5 \%$, suggesting that the dispersive Raman spectroscopy using optical probe can detect the amount of API presented in the commercial samples.

As the study of Szostak and Mazurek (2002) [27], the Raman model developed here using PLS was used to quantify the commercial samples containing acetaminophen, by applying the PLS model to the six samples of commercial drugs. Table 4 shows the results of the RS/PLS predicted concentrations and NIRS concentrations and the errors for the commercial medicine. The predicted concentrations were highly correlated to the concentration of the medicine presented in the label; all drugs fell below the $\pm 2.5 \%$ error limit, indicating excellent results in determining the API concentration. The same was done with the NIRS values, and the largest error found was $3.7 \%$. The present study used a fiber optic probe made up with low-OH fused-silica fibers, with the intention of getting reproducibility in the excitation/collection geometry of the volume sampled [20]. 
Table 3: Solutions of different concentrations $(160,200$, and $240 \mathrm{mg} / \mathrm{mL})$ used to calculate the precision (RSD) and accuracy (AC).

\begin{tabular}{|c|c|c|c|c|c|c|c|}
\hline $\begin{array}{l}\text { Real concentration } \\
(\mathrm{mg} / \mathrm{mL})\end{array}$ & $\begin{array}{c}\text { VO } \\
\text { RS/PLS } \\
\text { (mg/mL) }\end{array}$ & $\begin{array}{c}\mathrm{DAC} \\
(\mathrm{mg} / \mathrm{mL})\end{array}$ & $\begin{array}{c}\mathrm{SD} \\
(\mathrm{mg} / \mathrm{mL})\end{array}$ & RSD (\%) & $\begin{array}{c}\mathrm{AD} \\
(\mathrm{mg} / \mathrm{mL})\end{array}$ & $\mathrm{RD}(\%)$ & $\mathrm{AC}(\%)$ \\
\hline \multirow{6}{*}{160} & 168.5 & \multirow{6}{*}{167.7} & \multirow{6}{*}{1.0} & \multirow{6}{*}{0.6} & \multirow{6}{*}{-7.7} & \multirow{6}{*}{-4.6} & \multirow{6}{*}{104,8} \\
\hline & 166.8 & & & & & & \\
\hline & 168.1 & & & & & & \\
\hline & 167.1 & & & & & & \\
\hline & 169.2 & & & & & & \\
\hline & 166.7 & & & & & & \\
\hline \multirow{6}{*}{200} & 194.9 & \multirow{6}{*}{197.8} & \multirow{6}{*}{2.9} & \multirow{6}{*}{1.5} & \multirow{6}{*}{-2.2} & \multirow{6}{*}{-1.1} & \multirow{6}{*}{99.0} \\
\hline & 198.2 & & & & & & \\
\hline & 198.2 & & & & & & \\
\hline & 195.6 & & & & & & \\
\hline & 196.4 & & & & & & \\
\hline & 203.1 & & & & & & \\
\hline \multirow{6}{*}{240} & 223.6 & \multirow{6}{*}{$\begin{array}{l}224.8 \\
230.1^{\text {** }}\end{array}$} & \multirow{6}{*}{$\begin{array}{l}13.4 \\
4.0^{* *}\end{array}$} & \multirow{6}{*}{$\begin{array}{l}6.0 \\
1.7^{* *}\end{array}$} & \multirow{6}{*}{$-9.9^{* *}$} & \multirow{6}{*}{$-4.3^{* *}$} & \multirow{6}{*}{98.5} \\
\hline & 232.5 & & & & & & \\
\hline & 233.2 & & & & & & \\
\hline & *198.5 & & & & & & \\
\hline & 228.9 & & & & & & \\
\hline & 232.3 & & & & & & \\
\hline
\end{tabular}

${ }^{*}$ Outlier, ${ }^{* *}$ recalculated values after outlier being excluded.

In order to achieve optimum yield and product quality, the global pharmaceutical industry is searching for better methods for tracking drugs throughout the production process, since most of the high-performance techniques currently used need sample preparation using solvents, are destructive and time consuming, and mostly need expensive inputs [7, 30, 31]. Recent literature indicates that the dispersive Raman spectroscopy, combined with chemometric method PLS (RS/PLS), would meet the expectations for a reliable quantitative determination of active ingredients in pharmaceutical drugs [7, $32,33]$.

In complex systems, such as API in medicines and formulations, the classical univariate regression method may become unreliable because of possible band interactions and superimposition. The PLS method has been suitable for quantitative measurement in chemical analysis when applied to spectroscopic data [13], calculating the amount of API in prepared solutions or directly in the commercial medicines [14], quantification of nimesulide in excipient and commercial samples [26], and quantitative determination of acetylsalicylic acid and acetaminophen in tablets [27]. The PLS model showed a lower prediction error when using $l v=1$, indicating that only one spectral variation was found in the samples and is related to the changes in the acetaminophen concentration, since most of pharmaceuticals consist of a few APIs and a lot of additives [27]. Since the intensity of a Raman 
Table 4: RS/PLS and NIRS values used to calculate the concentrations of acetaminophen in six commercial medicines and the errors of each method.

\begin{tabular}{lccccc}
\hline $\begin{array}{l}\text { Commercial } \\
\text { medicines }\end{array}$ & $\begin{array}{c}\text { Nominal value } \\
(\mathrm{mg} / \mathrm{mL})\end{array}$ & $\begin{array}{c}\text { RS/PLS } \\
\text { concentration } \\
(\mathrm{mg} / \mathrm{mL})\end{array}$ & $\begin{array}{c}\text { Error RS/PLS } \\
(\mathrm{mg} / \mathrm{mL})\end{array}$ & $\begin{array}{c}\text { NIRS } \\
\text { concentration } \\
(\mathrm{mg} / \mathrm{mL})\end{array}$ & $\begin{array}{c}\text { Error NIRS } \\
(\mathrm{mg} / \mathrm{mL})\end{array}$ \\
\hline Med_1 & 200,0 & 201,3 & 0,7 & 202,0 & 1,0 \\
Med_2 & 200,0 & 202,7 & 1,4 & 204,0 & 2,0 \\
Med_3 & 200,0 & 199,0 & 0,5 & 207,4 & 3,7 \\
Med_4 & 200,0 & 201,5 & 0,8 & 202,0 & 1,0 \\
Med_5 & 200,0 & 201,4 & 0,7 & 204,0 & 2,0 \\
Med_6 & 200,0 & 203,8 & 1,9 & 206,4 & 3,2 \\
\hline
\end{tabular}

band is associated with changes in the polarizability of the molecules presented in the sample, this has a relevant consequence in investigating pharmaceutical materials because APIs usually contain aromatic conjugated systems which show strong Raman transitions and, in contrast, excipients are generally weaker Raman scatterers due to a lack of $\mathrm{C}$ bonds in most formulations [27].

According to the PAT guide, the gains in processes quality, safety, and/or efficiency can change depending on the product and these changes come from factors such as prevention of rejections, disposal, and reprocessing of products; possibility of carrying out analysis in real time with reduced or no sample preparation $[17,34]$, leading to a reduction of human error and increasing the safety of the operator and no risk to the environment $[5,18,19]$. The RS/PLS model could be able to address most of these factors, because each sample was irradiated rapidly and examined directly with the use of an optical probe, without prior preparation, in real time at line, which leads to minimization of human error.

\section{Conclusions}

This study demonstrated the effectiveness of the near-infrared dispersive Raman Spectroscopy with fiber optic probe as a quantitative method, with high linearity, selectivity $<2.5 \%$, precision $<5 \%$, and accuracy $<3 \%$, with recovery values of $<5 \%$ and SEP of $1.19 \mathrm{mg} / \mathrm{mL}(0.6 \%)$ for quantifying the acetaminophen diluted in excipient. For the quantification of API in the commercial formulation, the model showed concentration values as closer as $200 \mathrm{mg} / \mathrm{mL}$, with less than $2.5 \%$ error compared to the labeled concentration, while, by NIRS method, the error found was 3.7\%. These results suggest that RS/PLS with fiber optic probe could replace the NIRS method in quality control of the product under study, while maintaining the safety and efficacy.

\section{Acknowledgments}

V. G. Borio thanks CAPES/PROSUP for the Master Fellowship. L. Silveira Jr. and R. A. Nicolau thank CNPq for the Productivity Fellowship (process no. 305610/2008-2 and 314455/2009-4, respectively). H. P. M. de Oliveira thanks FAPESP (2006/56701-3) and CNPq (479655/2008-1) for the financial support. 


\section{References}

[1] M. E. Bosch, A. J. R. Sánchez, F. S. Rojas, and C. B. Ojeda, "Determination of paracetamol: historical evolution," Journal of Pharmaceutical and Biomedical Analysis, vol. 42, no. 3, pp. 291$321,2006$.

[2] M. Blanco, M. Bautista, and M. Alcalà, "API determination by NIR spectroscopy across pharmaceutical production process," AAPS PharmSciTech, vol. 9, no. 4, pp. 1130-1135, 2008.

[3] O. Kolomiets, U. Hoffmann, P. Geladi, and H. W. Siesler, "Quantitative determination of pharmaceutical drug formulations by near-infrared spectroscopic imaging," Applied Spectroscopy, vol. 62, no. 11, pp. 1200-1208, 2008.

[4] R. C. Lora, L. Silveira, S. R. Zamuner, and M. T. T. Pacheco, "Dispersive Raman spectroscopy for the in vitro identification and quantification of injected vancomycin intra-vitreous," Spectroscopy, vol. 25, no. 2, pp. 103-112, 2011.

[5] Y. Dou, Y. Sun, Y. Ren, P. Ju, and Y. Ren, "Simultaneous non-destructive determination of two components of combined paracetamol and amantadine hydrochloride in tablets and powder by NIR spectroscopy and artificial neural networks," Journal of Pharmaceutical and Biomedical Analysis, vol. 37, no. 3, pp. 543-549, 2005.

[6] T. Vankeirsbilck, A. Vercauteren, W. Baeyens et al., "Applications of Raman spectroscopy in pharmaceutical analysis," Trends in Analytical Chemistry, vol. 21, no. 12, pp. 869-877, 2002.

[7] C. Eliasson, N. A. Macleod, L. C. Jayes et al., "Non-invasive quantitative assessment of the content of pharmaceutical capsules using transmission Raman spectroscopy," Journal of Pharmaceutical and Biomedical Analysis, vol. 47, no. 2, pp. 221-229, 2008.

[8] E. B. Hanlon, R. Manoharan, T. W. Koo et al., "Prospects for in vivo Raman spectroscopy," Physics in Medicine and Biology, vol. 45, no. 2, pp. R1-R59, 2000.

[9] M. S. Hwang, S. Cho, H. Chung, and Y. A. Woo, "Nondestructive determination of the ambroxol content in tablets by Raman spectroscopy," Journal of Pharmaceutical and Biomedical Analysis, vol. 38, no. 2, pp. 210-215, 2005.

[10] L. M. Moreira, L. Silveira, F. V. Santos et al., "Raman spectroscopy: a powerful technique for biochemical analysis and diagnosis," Spectroscopy, vol. 22, no. 1, pp. 1-19, 2008.

[11] B. B. Koleva, T. M. Kolev, D. L. Tsalev, and M. Spiteller, "Determination of phenacetin and salophen analgetics in solid binary mixtures with caffeine by infrared linear dichroic and Raman spectroscopy," Journal of Pharmaceutical and Biomedical Analysis, vol. 46, no. 2, pp. 267-273, 2008.

[12] P. R. Mobley, B. R. Kowalski, J. J. Workman, and R. Bro, "Review of chemometrics applied to spectroscopy: 1985-95-part 2," Applied Spectroscopy Reviews, vol. 31, no. 4, pp. 347-368, 1996.

[13] M. M. C. Ferreira, A. M. Antunes, M. S. Melgo, and P. L. O. Volpe, "Chemometrics i: multivariate calibration, a tutorial," Quimica Nova, vol. 22, no. 5, pp. 724-731, 1999.

[14] M. M. Sena and R. J. Poppi, "N-way PLS applied to simultaneous spectrophotometric determination of acetylsalicylic acid, paracetamol and caffeine," Journal of Pharmaceutical and Biomedical Analysis, vol. 34, no. 1, pp. 27-34, 2004.

[15] F. Adar, R. Geiger, and J. Noonan, "Raman spectroscopy for process/quality control," Applied Spectroscopy Reviews, vol. 32, no. 1-2, pp. 45-101, 1997.

[16] G. Fini, "Application of Raman spectroscopy pharmacy," Journal of Raman Spectroscopy, vol. 35, no. 5, pp. 335-337, 2004.

[17] D. C. Hinz, "Process analytical technologies in the pharmaceutical industry: the FDA's PAT initiative," Analytical and Bioanalytical Chemistry, vol. 384, no. 5, pp. 1036-1042, 2006.

[18] Food and Drug Administration, "International conference on harmonisation. Guideline on validation of analytical procedures: definitions and terminology," Federal Register, vol. 60, no. 40, pp. 11259-11262, 1995. 
[19] Food and Drug Administration, "International conference on harmonisation; guideline on the validation of analytical procedures: methodology," Federal Register, vol. 62, no. 96, pp. 2746327467, 1997.

[20] C. J. De Lima, M. Simões, M. T. T. Pacheco, L. Silveira, and A. B. Villaverde, "Optical fiber catheter with distal end bending mechanism control for raman biospectroscopy," Instrumentation Science and Technology, vol. 36, no. 1, pp. 43-55, 2008.

[21] F. L. Silveira, L. Silveira, A. B. Villaverde, M. T. T. Pacheco, and C. A. Pasqualucci, "Use of dispersive raman spectroscopy in the determination of unsaturated fat in commercial edible oiland fat-containing industrialized foods," Instrumentation Science and Technology, vol. 38, no. 1, pp. 107-123, 2010.

[22] J. C. Lázaro, M. T. T. Pacheco, K. C. Rodrigues et al., "Optimizing the Raman signal for characterizing organic samples: the effect of slit aperture and exposure time," Spectroscopy, vol. 23, no. 2, pp. 71-80, 2009.

[23] A. P. Da Cunha, V. D. P. Prisco Da Cunha, L. Silveira, and A. A. Martin, "Calibration model of methylmetacrylate concentration in aqueous solution using ultraviolet absorption spectroscopy," Quimica Nova, vol. 26, no. 6, pp. 850-854, 2003.

[24] L. Silveira, L. M. Moreira, V. G. B. Conceição et al., "Determination of sucrose concentration in lemon-type soft drinks by dispersive Raman spectroscopy," Spectroscopy, vol. 23, no. 3-4, pp. 217-226, 2009.

[25] H. A. Moynihan and I. P. O'Hare, "Spectroscopic characterisation of the monoclinic and orthorhombic forms of paracetamol," International Journal of Pharmaceutics, vol. 247, no. 1-2, pp. 179$185,2002$.

[26] W. F. C. Rocha, A. L. Rosa, J. A. Martins, and R. J. Poppi, "Determination and validation of nimesulide in pharmaceutical formulation by near infrared spectroscopy," Journal of the Brazilian Chemical Society, vol. 21, no. 10, pp. 1929-1936, 2010.

[27] R. Szostak and S. Mazurek, "Quantitative determination of acetylsalicylic acid and acetaminophen in tablets by FT-Raman spectroscopy," Analyst, vol. 127, no. 1, pp. 144-148, 2002.

[28] M. G. Orkoula, C. G. Kontoyannis, C. K. Markopoulou, and J. E. Koundourellis, "Quantitative analysis of liquid formulations using FT-Raman spectroscopy and HPLC. The case of diphenhydramine hydrochloride in Benadryl@," Journal of Pharmaceutical and Biomedical Analysis, vol. 41, no. 4, pp. 1406-1411, 2006.

[29] P. Rossignoli, R. Pontarolo, C. J. Correr, G. Cordeiro, and P. Peralta-Zamora, "Multivariate spectroscopic determination of glucosamine and chondroitin in pharmaceutical formulations," Quimica Nova, vol. 31, no. 6, pp. 1285-1289, 2008.

[30] B. A. Olsen, "Developing and using analytical methods to achieve quality by design and efficiency in drug development," Pharmaceutical Technology, pp. S14-S25, 2005.

[31] A. S. Rathore, R. Bhambure, and V. Ghare, "Process analytical technology (PAT) for biopharmaceutical products," Analytical and Bioanalytical Chemistry, vol. 398, no. 1, pp. 137-154, 2010.

[32] E. Katainen, M. Elomaa, U. M. Laakkonen et al., "Quantification of the amphetamine content in seized street samples by Raman spectroscopy," Journal of Forensic Sciences, vol. 52, no. 1, pp. 88-92, 2007.

[33] M. Kim, H. Chung, Y. Woo, and M. S. Kemper, "A new non-invasive, quantitative Raman technique for the determination of an active ingredient in pharmaceutical liquids by direct measurement through a plastic bottle," Analytica Chimica Acta, vol. 587, no. 2, pp. 200-207, 2007.

[34] Food and Drug Administration, "Guidance for Industry PAT-A Framework for Innovative Pharmaceutical Development, Manufacturing, and Quality Assurance," 2010, http://www.fda.gov/ downloads/Drugs/GuidanceComplianceRegulatoryInformation/Guidances/UCM070305.pdf. 


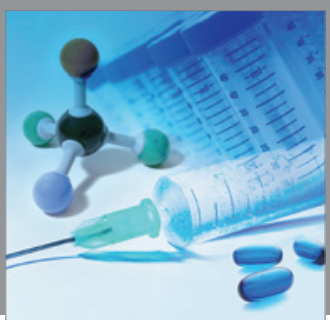

International Journal of

Medicinal Chemistry

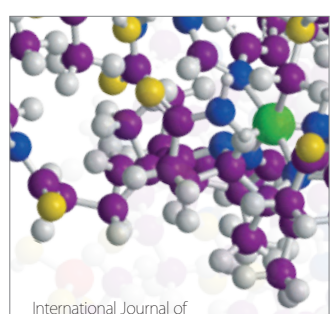

Carbohydrate Chemistry

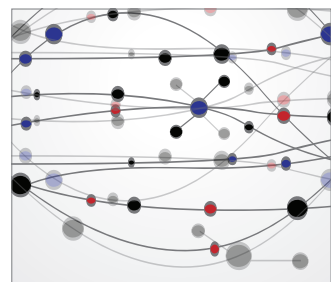

The Scientific World Journal
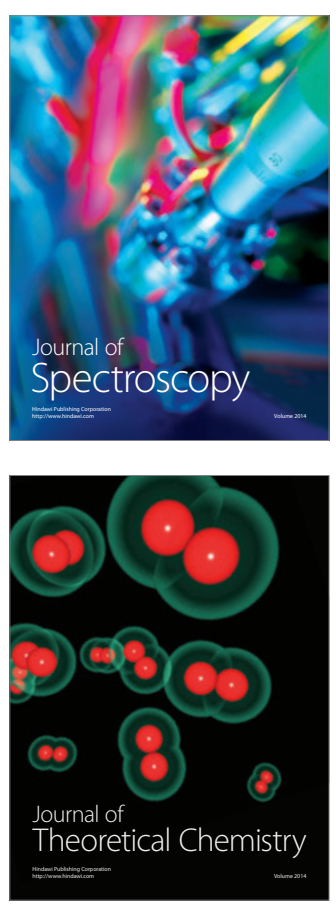
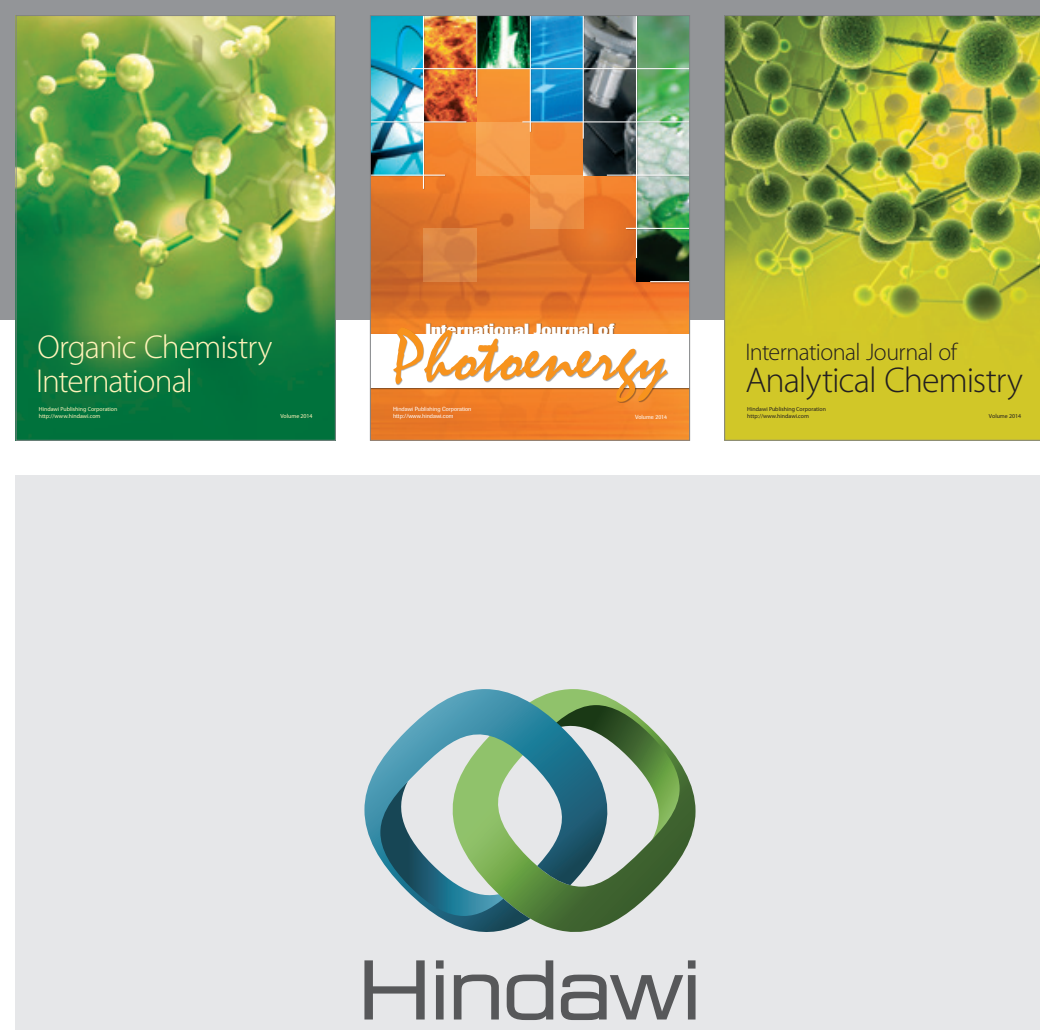

Submit your manuscripts at

http://www.hindawi.com
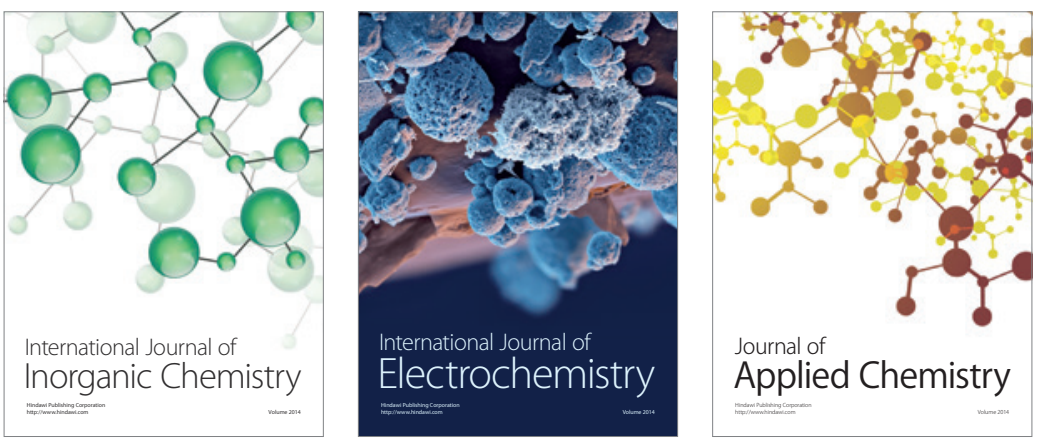

Journal of

Applied Chemistry
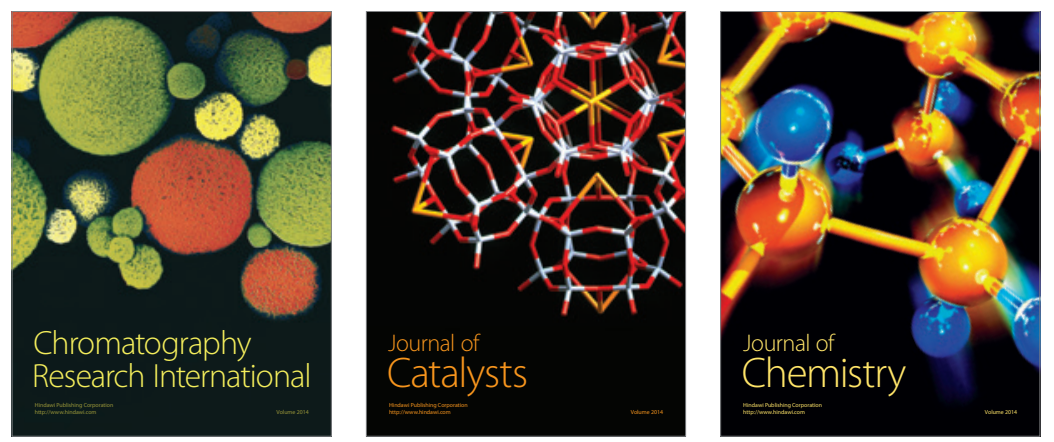
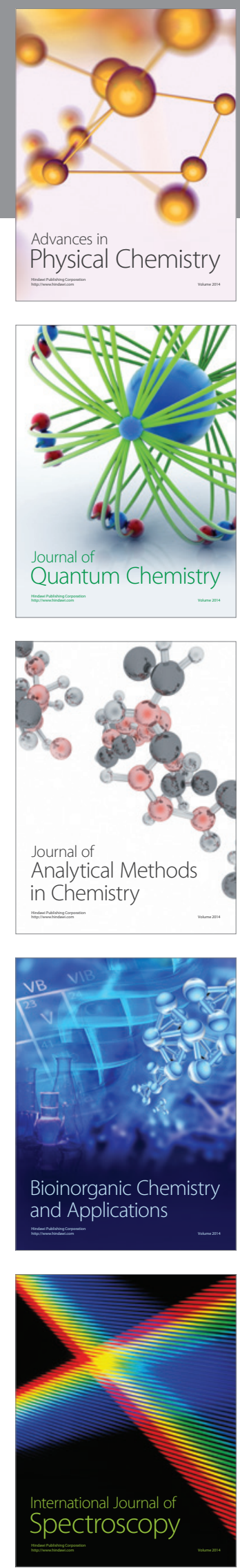